Bulletin of Pharmaceutical Sciences
Assiut University

\title{
B (REG) CELLS IN HEPATITIS C VIRUS AND DIABETES
}

Khaled Mohammed Hassanin ${ }^{1}$, Omnia Hassan Bakr ${ }^{1}$, Helal Fouad Hetta ${ }^{1}$, Mohamed Omar Abdel malek ${ }^{1}$ and Fadwa Ali Mohammed ${ }^{2 *}$

${ }^{1}$ Department of Medical Microbiology and Immunology, Faculty of Medicine, Assiut University, Assiut, Egypt

${ }^{2}$ Assiut Center Administration, Assiut, Egypt

Over the last decade it has become evident that in addition to producing antibody, B cells activate the immune system by producing cytokines and via antigen presentation. In addition, $B$ cells also exhibit immunosuppressive functions via diverse regulatory mechanisms. This subset of $B$ cells, known as regulatory B cells (B regs), contributes to the maintenance of tolerance, primarily via the production of IL-10. Studies in experimental animal models, as well as in patients with autoimmune diseases, have identified multiple B(reg) subsets exhibiting diverse mechanisms of immune suppression. In this review, we describe the different B(reg) subsets identified in humans, and their diverse mechanisms of suppression in HCV and diabetic patients.

Aims: The main objectives of the study are to identify the role of $B(r e g)$ in the hepatitis $C$ virus infected patients and diabetes.

\section{INTRODUCTION}

\section{Hepatitis $\mathrm{C}$ virus}

Hepatitis $\mathrm{C}$ virus (HCV) is an important human pathogen that causes hepatitis, liver cirrhosis and hepatocellular carcinoma ${ }^{1}$. HCV is a small single-stranded ribonucleic acid (RNA) of positive polarity, and is an enveloped virus belonging to the Hepacivirus genus within the Flaviviridae family ${ }^{2}$. The total length of RNA genome is about $9.6 \mathrm{~kb}$ with one open reading frame (ORF) and 50 and 30 untranslated regions (UTRs) at both edges ${ }^{3}$.

$\mathrm{HCV}$ particles are $50-80 \mathrm{~nm}$ in diameter ${ }^{4}$ and contain the single-stranded RNA genome, core and the envelope glycoproteins, E1 and $\mathrm{E} 2^{5}$. The HCV genome interacts with the core protein to form the nucleocapsid that is surrounded by a lipid membrane, called the viral envelope, in which the envelope glycoproteins are anchored. Importantly, due to virion association with lipoproteins, apolipoproteins such as apoE, apoB, apoA1, apoC1, apoC2, and apoC3 can also be found in association with HCV particles (Fig. 1).

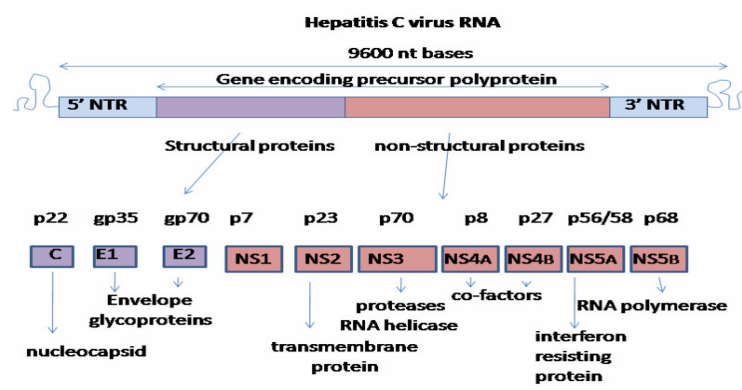

Fig. 1: Hepatitis $C$ virus complete genome ${ }^{6}$.

In developing countries $\mathrm{HCV}$ is transmitted by IVDU, sexualexposure and blood products ${ }^{7}$. Symptoms can appear anytime from 2 weeks to 6 monthsafter a person is infected with the virus. Symptoms include jaundice, fatigue, gray-colored stool, joint pain, belly pain, weakness, anorexia, itchy skin and dark urine. Mild cognitive problems and fatigue are the major symptoms of chronic hepatitis $\mathrm{C}^{8}$.

Egypt has the highest prevalence of HCV in the world. Nearly 15 million Egyptians

Received in 4/4/2019 \& Accepted in 1/8/2019 
currently suffer from HCV, with 40,000 dying from the disease each year ${ }^{9}$. Genotype 4 is the predominant genotype, which accounts for more than $90 \%$ of infections ${ }^{10 \& 11}$.

Most infected individuals have no symptoms during the acute infection, although $15-30 \%$ may experience non-specific symptoms $^{12}$. Because most acute HCV infections are sub-clinical, it is difficult to calculate how many patients clear HCV without treatment ${ }^{12}$. This typically occurs in the first 6 months after exposure and is estimated to be between $<20 \%$ and about $50 \%$ in different populations ${ }^{13}$; spontaneous clearance is affected by host genetics, race, age, sex, and comorbidities such as $\mathrm{HIV}^{14}$.

\section{Immune response to hepatitis $\mathrm{C}$ virus}

\section{Innate immune responses to $\mathrm{HCV}$ infection}

Soon after establishing infection in hepatic foci, HCV undergoes an exponential 'ramp-up' phase of replication ${ }^{15}$; the rate of increase decreases abruptly when cells in the liver express a host of IFN-stimulated genes (ISGs) that limit $\mathrm{HCV}$ replication and spread ${ }^{16}$. Innate immunity is a first line of defence against HCV infection ${ }^{15}$ and stimulates adaptive immunity. HCV RNA binds to retinoic acid-inducible gene I, activating mitochondrial antiviral signalling (MAVS) proteins; double-stranded RNA bound to Toll-like receptor- 3 induces signalling via TIR domain-containing adaptor inducing IFN-b (TRIF). Both pathways activate nuclear factor kappa-lightchain- enhancer of activated $\mathrm{B}$ cells (NFkB) and interferon regulatory factor 3 (IRF3) translocation to the nucleus. Here, they promote expression of IFNs and ISGs to inhibit viral replication, plus proinflammatory and chemokines to recruit and activate immune cells. HCV's NS3-4A protease specifically cleaves MAVS and TRIF to dampen IFN induction ${ }^{17}$. Hepatocytes preferentially express IFN-1 following HCV infection ${ }^{18}$. Dendritic cells, Kupffer cells, and other nonparenchymal cells also recognize viral molecular patterns, contributing to IFN and cytokine production and response without themselves harbouring replicating $\mathrm{HCV}^{15 \& 17}$.

\section{Cellular immune response to $\mathrm{HCV}$ infection}

The adaptive immune response includes two major types of effector mechanisms: cellular responses comprising $\mathrm{CD} 4 \mathrm{~T}$ helper
(Th) cells and cytotoxic CD8 T lymphocytes (CTL); and humoral responses consisting of antibodies produced by $\mathrm{HCV}$-specific B cells. Recognition of a specific viral epitope/protein is required for both adaptive immune effector mechanisms, which can target any $\mathrm{HCV}$ protein. However, only some B cell epitopes localized on the viral envelope or capsid proteins can induce $\mathrm{HCV}$ neutralizing antibodies and efficiently prevent the binding and entry of the virus, i.e., prevent $\mathrm{HCV}$ infection. Activated dendritic cells can present $\mathrm{HCV}$ antigens to specific Th cells that respond by proliferation and production of cytokines such as interleukin (IL)-2, IFN- $\gamma$ or IL-4. Th cell activation and cytokine production is required for the development of CTL. Ideally, stimulated CTL found in the liver will lyse HCVinfected liver cells by cytolytic and noncytolytic mechanisms ${ }^{19}$.

\section{Acute infection and chronic infection}

Acute hepatitis $\mathrm{C}$ infection is infrequently diagnosed as the majority of acutely infected individuals are asymptomatic. Chronic hepatitis $\mathrm{C}$ is marked by the persistence of HCV-RNA in the blood for at least 6 months after onset of acute infection ${ }^{20}$.

\section{Diagnosis and genotyping of $\mathrm{HCV}$}

HCV-RNA by PCR is the quickest and most informative method for HCV detection, while long infection time is required to detect virus using antibodies ${ }^{21}$. The hepatitis $\mathrm{C}$ diagnosis mostly depends on serological assay and HCVRNA ${ }^{22}$.

\section{New lines of treatment of hev}

Treatment with antiviral medication is recommended in all people with proven chronic hepatitis $\mathrm{C}$ who are not at high risk of dying from other causes. People with the highest complication risk should be treated first, with the risk of complications based on the degree of liver scarring.

In 2016, the American Association for the Study of Liver Diseases and the Infectious Diseases Society of America jointly published a recommendation for the management of hepatitis C. In this recommendation, sofosbuvir and ledipasvir, or sofosbuvir and ribavirin, with or without peg interferon, are part of all firstline treatments for $\mathrm{HCV}$ genotypes 1 to 6 , and 
are also part of some second-line treatments ${ }^{23 \& 24}$.

\section{Type 2 diabetes mellitus (T2DM)}

Diabetes mellitus is a heterogeneous and complex disease characterized by chronic hyperglycemia. Type 2 diabetes mellitus (T2DM), characterized by a variable defect of insulin secretion and action, is by far the most common cause, accounting for $>90 \%$ of cases $^{25}$.

Over the past decades, there has been a major increase in type 2 diabetes (T2D) prevalence in most regions of the world ${ }^{26}$. After adjusting for the impact of ageing populations, diabetes prevalence in adults (85-95\% T2D) almost doubled between 1980 and 2014 worldwide. Increases were more pronounced in low- and middle-income countries and in men compared to women ${ }^{26}$.

This increase in type 2 diabetes is inextricably linked to changes towards a western lifestyle (high-energy diets with reduced physical activity) in developing countries and the rise in the prevalence of overweight and obesity ${ }^{27}$.

The International Diabetes Federation (IDF) listed Egypt among the world top 10 countries in the number of patients with diabetes. Currently, diabetes is a leading cause of vision loss in Egypt. It is estimated that $42 \%$ of patients with diabetes in Egypt have diabetic retinopathy, $5 \%$ are legally blind, and $22 \%$ had peripheral neuropathy. Diabetes is also the major cause of end-stage renal disease and leg amputation in Egypt $^{25}$.

T2DM is characterized by defective and delayed insulin secretion as well as abnormal postprandial suppression of glucagon. These abnormalities explainthe defective suppression of endogenous glucose production after a meal; this, combined with decreased peripheral glucose uptake, contributes to postprandial hyperglycemia. The islets of people with longstanding T2DM have a characteristic appearance, with prominent amyloid deposition and a decrease in functional $\beta$-cells. These anatomical defects underlie the decrease in insulin secretion (Fig. 2).

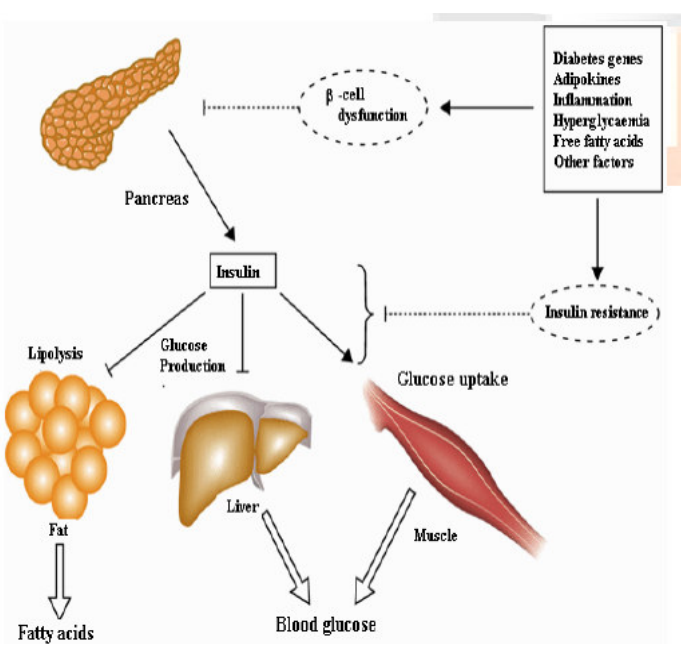

Fig. 2: Showing pathophysiology of type II Diabetes $^{28}$.

The most significant symptoms of diabetes

Symptoms of marked hyperglycemia include polyuria, polydipsia, weight loss, sometimes with polyphagia, and blurred vision. Impairment of growth and susceptibility to certain infections may also accompany chronic hyperglycemia. Acute, life-threatening consequences of uncontrolled diabetes are hyperglycemia with ketoacidosis or the nonketotic hyperosmolar syndrome ${ }^{29}$.

\section{Hepatitis C Virus and insulin resistance /diabetes mellitus}

A potential synergism exists between $\mathrm{HCV}$ infection and diabetes and this is attributed to multi-level and multi-faceted interactions between $\mathrm{HCV}$ and glucose metabolism. Allison et al. ${ }^{30}$ first reported an increased prevalence of diabetes mellitus in patients with HCV associated liver cirrhosis but the categorization of diabetes was not possible initially due to lack of genetic and immunological data ${ }^{31}$.

$\mathrm{HCV}$ infections can trigger autoimmune reactions against pancreatic $\beta$-cellsin genetically susceptible subjects leading to direct destruction of $\mathrm{b}$ cells thereby causing type 1 diabetes $^{32}$. Conversely, a complex interaction between insulin resistance (IR), hepatic steatosis and inflammatory cytokines have been implicated for the development of type 2 diabetes in HCV infected individuals ${ }^{33}$. $\mathrm{HCV}$ causes alteration in hepatic carbohydrate and lipid metabolism and has also been linked 
with modifications of molecular mechanisms like oxidative stress, mitochondrial function, signalling in the insulin receptor substrate-1 pathway and influences on the activities of proinflammatory cytokines and adipokines ${ }^{34}$. This creates an environment for metabolic syndrome leading to altered glucose homeostasis resulting in impaired glucose tolerance and type 2 diabetes. HCV infection is the most common indication for liver transplantation. Patients may either have pre-existing diabetes mellitus (PDM) or may develop new-onset diabetes after transplant (NODAT) ${ }^{35}$. In the first year post-transplant, diabetes is most likely due to intense immunosuppression which potentiates the dysglycaemic effects of HCV by enhancing viral replication ${ }^{36}$. This potentially resolves after the immunosuppressive regimen is stabilized but long-term diabetes (pre-existing and NODAT) may persist, leading to advanced hepatic fibrosis and graft failure ${ }^{35}$.

\section{B (reg) cells}

In 2002, Mizoguchi and collaborators introduced the term "regulatory B cells" and identified B (regs) as an IL- 10-producing B cell subset ${ }^{37}$. B (reg) cells have been identified as a negative regulator of the immune system that inhibit pathological immune response by suppressing both uncontrolled protective immune response and damaging autoimmune responses. The mechanism by which B (regs) suppress inflammatory responses is mainly via the production of $\mathrm{IL}-10^{38}$. Mauri et al. ${ }^{39}$ reported that B (regs) arise from a common progenitor named transitional 2 marginal zone precursor (T2-MZP) B cells ${ }^{40}$ as they have most of the indicated markers for $\mathrm{B}$ (regs) ${ }^{39}$. Human regulatory B-cells or also known as human IL-10 producing B cells are a subset of $\mathrm{B}$ cells is enriched in the CD19+ CD24highCD27 - CD38highCD1dhighCD5 + transitional B cell subset. Additionally, these B cells are highly enriched in IL-10 expressing B (B10) cells $^{41}$. In the presence of toll like receptor (TLR) ligands, the inflammation cascade initiated and $\mathrm{B}$ cells receive $\mathrm{BCR}$, CD40, or CD80/CD86 activating signals leading to release IL-10 ${ }^{39}$. IL-10 playsan essential role in inducing immuno regulatory phenotype of B cells that exert massive antiinflammatory and immuno suppressive actions $^{42}$.

\section{Mechanism of action}

Human B regulatory cells (B regs) effector mechanisms. B (regs) can secrete different antiinflammatory cytokines such as interleukin 10 (IL-10), transforming growth factor $\beta$ and IL35. They also express surface molecules including CD80, CD86, or PD-L1 that mediates suppression by direct cell-cell interactions. B (regs) can also use enzymes to exert its effects in target cells; these are for example intracellular granzyme $\mathrm{B}$ or indoleaminepyrrole 2, 3-dioxygenase or the membraneexpressed CD73 that mediates the generation of adenosine. Finally, some B (regs) subsets can also switch to produce immunoglobulin 4 after activation; a secreted immunoglobulin also related with immune-suppressive functions. Collectively, these elements can suppress the functionality of lymphoid (inhibiting for example the IL-17 or interferon$\gamma$ production by Th17, Th1 or T CD8+ cells) or myeloid (preventing the secretion of tumor necrosis factor- $\alpha$ or $\mathrm{IL}-12$ by inflammatory monocytes or dendritic cells, respectively). In addition, B (regs) can also enhance the effector abilities of B (regs) (promoting IL10 secretion) and invariant natural killer cells (inducing them to produce IL-4 and IL-13) to favor an anti-inflammatory microenvironment ${ }^{43}$ (Fig. 3).

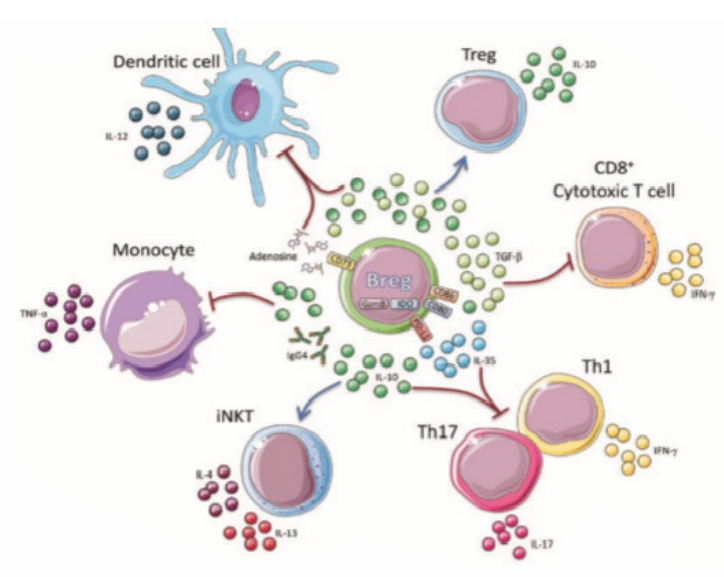

Fig. 3: Mechanism of B (reg) cells ${ }^{43}$. 
Role of B (reg) cells in $\mathrm{HCV}$ infection and diabetes

Regulatory B (B reg) cells, both in mice and humans, are a potent regulatory component of the immune system. Regulatory B cells (B regs) may act earlier than regulatory $T$ cells ( $T$ regs) and may play as important a role in autoimmune and allergic diseases ${ }^{44}$. During the pathogenic process of $\mathrm{CHC}$, many patients develop immunodeficiency and impaired virusspecific responses. However, the mechanisms underlying virus-specific immune impairment have not been clarified. Immuno regulatory cells, such as $\mathrm{IL}-10+\mathrm{B}$ (regs), T (regs) and TFR cells have been shown to down-regulate immunity ${ }^{45}$. Numbers of circulating IL-10 + B (regs) in CHC patients were greater than in the healthy donors ${ }^{46}$. The hepatitis $\mathrm{C}$ virus eludes the host immune response by stimulating some of the B (reg) cells in the mucous membranes ${ }^{47}$.

$B$ (regs) play an important role in shaping $\mathrm{T}$ cell responses ${ }^{48}$. IL-10 + B (regs) have been shown to inhibit antigen-presenting activity and immune response ${ }^{49}$.

Previous studies have shown that $\mathrm{T}$ cell immunity, particularly for virus-specific CD8+ $\mathrm{T}$ cell responses, is crucial for the control of virus replication and liver-injury during the pathogenic process of $\mathrm{CHC}^{50}$. Given that $\mathrm{IL}-10$ is a potent inhibitor of $\mathrm{T}$ cell immunity, it is possible that IL-10 secreted by B (regs) downregulates $\mathrm{T}$ cell immunity and impairs virus eradication. In addition, IL-10 + B (regs) may promote the development of functional $\mathrm{T}$ (regs), impairing anti-virus $\mathrm{T}$ cells immunity. Furthermore, levels of serum IL-2, IFN- $\gamma$ and TNF- $\alpha$ were significantly changed in the CHC patients. However, the precise mechanisms underlying the regulatory effect of IL-10 + B (regs) and the association of these regulatory cells with the change in the levels of proinflammatory cytokines remain to be investigated. IL-10 + B (reg) cells may secrete TGF- $\beta 1$, which activates the Smad signaling to promote liver fibrosis and to induce other unknown factors, causing liver injury in those CHC patients ${ }^{46}$. Chronic HCV infection not only causes continual liver damages, but also is associated with the development of cirrhosis and $\mathrm{HCC}^{43}$.

B (regs) may suppress the antitumor immunity and promote HCC progression via several mechanisms including the CD40
/CD40L signaling-mediated cytokine production of IL10, TGF- $\beta$ which down regulate TNF- $\alpha$ which is crucial for antitumor immunity $^{51}$. Depletion of B (reg) or blockage e of CD40/CD154 interaction between B (reg) and HCC cells might be a future novel therapeutic approach in treatment of $\mathrm{HCC}$ because inhibition of this pathway will decrease the secretion of IL10, TGF- $\beta 1$ but increase in the level of TNF- $\alpha$ which inhibit tumor growth ${ }^{51}$. There is strong evidence that $\mathrm{B}$ (reg) interact with $\mathrm{T}(\mathrm{reg})$ in the tumor micro environment; B (reg) may induce the conversion of resting CD4+ T cells into $\mathrm{T}$ (reg) to support tumor progression and metastasis by suppressing the $\mathrm{T}$ cell anticancer immune response $^{52}$.

B cells play a pathogenic role in the initiation of type 1 diabetes(T1D) in NOD mice $^{53}$, which is a Th1-mediated autoimmune disease $^{54}$. However, activated B cells can also maintain tolerance and transfer protection from T1D in this mouse model ${ }^{55}$. The repeated intravenous transfusion of 1.2-107 BCR stimulated NOD spleen B cells into NOD mice starting at 5-6weeks of age both delays the onset and reduces the incidence ofT1D, while treatment at 9 weeks of age before disease onset onlydelays T1D onset. Protection from T1D requires B-cell IL-10 productions, because the transfusion of activated NOD-IL-10B cells does not confer protection from T1D or the severe insulitis observed in the islets of NOD recipients. The therapeutic effect of transfusing activated NOD B cells correlates with polarization of CD41 T-cell response toward a Th2 phenotype. These findings suggest the possibility that therapeutic transfusion of autologous IL-10-producing BCR-activated B cells may protect human subjects at risk for T1D.

\section{Discussion}

The prevalence of Hepatitis C Virus (HCV) infection varies throughout the world, the highest rate reported in Egypt and it is a major cause of chronic hepatitis, liver cirrhosis, hepatocellular carcinoma and transplantation in the country ${ }^{56}$

A main characteristic feature of $\mathrm{HCV}$ infection is its persistent nature and high frequency of chronicity. Chronic hepatitis may progress into liver cirrhosis (LC). After 
cirrhosis has been diagnosed the incidence of $\mathrm{HCC}$ is roughly $2 \%$ of patients/year ${ }^{57}$

Type 2 diabetes (T2D) is one of the major global human health problems. In Egypt, the prevalence of T2D is around $15.56 \%$ among adults between 20 and 79 years of age, with an annual death of 86,478 related to diabetes ${ }^{58}$. In 2013, the International Diabetes Federation (IDF) estimated that 7.5 million individuals have diabetes and around 2.2 million have prediabetes. Furthermore, reports indicate that $43 \%$ of patients with diabetes and most patients with prediabetes in Egypt are likely undiagnosed $^{25}$.

Various studies reported that the T2D tends to increase the HCC development and induces a poor prognosis for those patients, in both presence or absence of cirrhosis ${ }^{59}$. It has been recognized as a cofactor that may modify the course of $\mathrm{HCV}$ infection, as well as functioning as an independent predictor of $\mathrm{HCC}^{60}$. Hence, the search for specific immunological markers, which follow the progression of $\mathrm{HCV}$ to $\mathrm{LC}$ in association with T2D, has become a topic of great scientific interest.

T2D can affect liver functions as was mentioned by ${ }^{61}$. Individuals with T2D have a higher incidence of liver function tests abnormalities than individuals who do not have diabetes. They explained this by postulating different mechanisms; the excess in free fatty acids found in the insulin-resistant state is known to be directly toxic to hepatocytes. Other mechanisms include cell membrane disruption at high concentration, mitochondrial dysfunction, toxin formation, and activation and inhibition of key steps in the regulation of metabolism.

B (regs) play an important role in shaping $\mathrm{T}$ cell responses (Yoshizaki, Miyagaki et al. 2012). IL-10 + B (regs) have been shown to inhibit antigen-presenting activity and immune response (Yanaba, Bouaziz et al. 2009). It is possible that the systemic inflammatory state caused by hepatitis induces the expansion of peripheral B (regs) (Chen, Song et al. 2012). Immuno regulatory cells, such as IL-10 + B (regs), T (regs) and TFR cells have been shown to down-regulate immunity ${ }^{45} . \mathrm{So}^{44}$. During the pathogenic process of $\mathrm{CHC}$, many patients develop immunodeficiency and impaired virusspecific responses.

\section{Conclusion}

Clearly, B (regs) are critical for tolerance maintenance and for the suppression of inflammation. B regstargeted therapies, aside from their potential risks or the lack of understanding of their mechanisms of action, now emerge as a challenging treatment option that shows great promise and could represent a new tactic to deal with immune-related diseases.

\section{REFERENCE}

1- J. Dubuisson and F. L. Cosset, "Virology and cell biology of the hepatitis $\mathrm{C}$ virus life cycle", An update, Journal of Hepatology, 61 (1 Suppl), S3-S13 (2014).

2- M. V. Preciado, P. Valva, A. EscobarGutierrez, P. Rahal, K. Ruiz-Tovar, L. Yamasaki, et al., "Hepatitis C virus molecular evolution: Transmission, disease progression and antiviral therapy", World Journal of Gastroenterology, 20 (43), 15992 (2014).

3- P. Simmonds, "Genetic diversity and evolution of hepatitis C virus-15 years on", Journal of General Virology, 85 (11), 3173-88 (2004).

4- M. T. Catanese, K. Uryu, M. Kopp, T. J. Edwards, L. Andrus, W. J. Rice, et al., "Ultrastructural analysis of hepatitis C virus particles", Proceedings of the National Academy of Sciences of the United States of America, 110 (23), 950510 (2013).

5- G. Vieyres, J. Dubuisson and T. Pietschmann, "Incorporation of hepatitis C virus E1 and E2 glycoproteins: The keystones on a peculiar virion", Viruses, 6 (3), 1149-87 (2014).

6- N. Kato, "Genome of human hepatitis $\mathrm{C}$ virus (HCV): Gene organization, sequence diversity, and variation", Microb. Comp. Genomics, (2000).

7- S. Ali, I. Ali, S. Azam and B. Ahmad, "Frequency distribution of $\mathrm{HCV}$ genotypes among chronic hepatitis $\mathrm{C}$ patients of Khyber Pakhtunkhwa", Virology Journal, 8 (1), 193 (2011).

8- S. L. Chen and T. R. Morgan, "The natural history of hepatitis $\mathrm{C}$ virus (HCV) infection", International Journal of Medical Sciences, 3 (2), 47 (2006). 
9- A. Gomaa, N. Allam, A. Elsharkway, M. El Kassas and I. Waked, "Hepatitis C infection in Egypt: prevalence, impact and management strategies", Hepatic Medicine: Evidence and Research, 9-17 (2017).

10- S. P. Kouyoumjian, H. Chemaitelly and L. J. Abu-Raddad, "Characterizing hepatitis $\mathrm{C}$ virus epidemiology in Egypt: Systematic reviews, meta-analyses, and metaregressions", Sci. Rep., 8 (1), 1661 (2018).

11- M. Mehta, H. F. Hetta, E. A. Abdelhameed, S. D. Rouster, M. Hossain, M. A. Mekky, et al., "Association between IL28B rs12979860 single nucleotide polymorphism and the frequency of colonic $\mathrm{T}$ (reg) in chronically HCVinfected patients", Arch. Virol., 161 (11), 3161-9 (2016).

12- B. Hajarizadeh, J. Grebely and G. J. Dore, "Epidemiology and natural history of HCV infection", Nature reviews, Gastroenterology \& Hepatology, 10 (9), 553-62 (2013).

13- R. H. Westbrook and G. Dusheiko, "Natural history of hepatitis C", Journal of Hepatology, 61 (1 Suppl), S58-68 (2014).

14- D. L. Thomas, C. L. Thio, M. P. Martin, Y. Qi, D. Ge, C. O'huigin, et al., "Genetic variation in IL28B and spontaneous clearance of hepatitis C virus", Nature, 461 (7265), 798 (2009).

15- L. B.Dustin, "Too low to measure, infectious nonetheless", Blood, 119 (26), 6181-2 (2012).

16- L. B. Dustin, S. B. Cashman and S. M. Laidlaw, "Immune control and failure in $\mathrm{HCV}$ infection-tipping the balance", Journal of Leukocyte Biology, 96 (4), 535-48 (2014).

17- S. M. Horner and Jr. M. Gale, "Regulation of hepatic innate immunity by hepatitis C virus", Nature Medicine, 19 (7), 879 (2013).

18- S. M. Laidlaw and L. B. Dustin, "Interferon lambda: Opportunities, risks, and uncertainties in the fight against HCV", Frontiers in Immunology, 5, 545 (2014).
19- S. F. Abdelwahab, "Cellular immune response to hepatitis-C-virus in subjects without viremia or seroconversion: Is it important?", Infectious Agents and Cancer, 11 (1), 23 (2016).

20- F. Kanwal, J. R. Kramer, J. Ilyas, Z. Duan and H. B. El-Serag, "HCV genotype 3 is associated with an increased risk of cirrhosis and hepatocellular cancer in a national sample of US Veterans with HCV", Hepatology, 60 (1), 98-105 (2014).

21- R. Ozaras and V. Tahan, "Acute hepatitis C: prevention and treatment", Expert Review of Anti-Infective Therapy, 7 (3), 351-61 (2009).

22- F. Nouroz, S. Shaheen, G. Mujtaba and S. Noreen, "An overview on hepatitis $C$ virus genotypes and its control", Egyptian Journal of Medical Human Genetics, 16 (4), 291-8 (2015).

23- I. AASLD, "HCV Guidance: Recommendations for Testing. Managing, and Treating Hepatitis C" (2016).

24- Liver KAftSot, "KASL clinical practice guidelines: Management of hepatitis C", Clinical and Molecular Hepatology, 22 (1), 76 (2016).

25- R. Hegazi, M. El-Gamal, N. Abdel-Hady and O. Hamdy, "Epidemiology of and Risk Factors for Type 2 Diabetes in Egypt", Annals of Global Health, 81 (6), 814-20 (2015).

26- H. Kolb and S. Martin, "Environmental/lifestyle factors in the pathogenesis and prevention of type 2 diabetes", BMC Medicine, 15 (1), 131 (2017).

27- J. C. Chan, V. Malik, W. Jia, T. Kadowaki, C. S. Yajnik, K-H. Yoon, et al., "Diabetes in Asia: Epidemiology, risk factors, and pathophysiology", Jama., 301 (20), 2129-40 (2009).

28- H. Baynes, "Classification, pathophysiology, diagnosis and management of diabetes mellitus", $\boldsymbol{J}$. Diabetes Metab., 6 (5), 1-9 (2015).

29- W. F. Rayburn, "Diagnosis and classification of diabetes mellitus: Highlights from the American Diabetes Association", The Journal of Reproductive Medicine, 42 (9), 585-6 (1997). 
30. M. E. Allison, T. Wreghitt, C. R. Palmer and G. J. Alexander, "Evidence for a link between hepatitis $\mathrm{C}$ virus infection and diabetes mellitus in a cirrhotic population", Journal of Hepatology, 21 (6), 1135-9 (1994).

31- A. L. Mason, J. Y. Lau, N. Hoang, K. Qian, G. J. Alexander, L. Xu, et al., "Association of diabetes mellitus and chronic hepatitis C virus infection", Hepatology, 29 (2), 328-33 (1999).

32- M. A. Atkinson and G. S. Eisenbarth, "Type 1 diabetes: New perspectives on disease pathogenesis and treatment", The Lancet., 358 (9277), 221-9 (2001).

33- S. Z. Safi, H. Shah, G. O. S. Yan and R. Qvist, "Insulin resistance provides the connection between hepatitis $\mathrm{C}$ virus and diabetes", Hepatitis Monthly, 15 (1), 1 (2015).

34- H. Noto and P. Raskin, "Hepatitis C infection and diabetes", Journal of Diabetes and its Complications, 20 (2), 113-20 (2006).

35- K. A. Morbitzer, D. J. Taber, N. A. Pilch, H. B. Meadows, J. N. Fleming, C. F. Bratton, et al., "The impact of diabetes mellitus and glycemic control on clinical outcomes following liver transplant for hepatitis C", Clinical Transplantation, 28 (8), 862-8 (2014).

36- Z. Younossi, M. Stepanova, S. Saab, G. Trimble, A. Mishra and L. Henry, "The association of hepatitis $\mathrm{C}$ virus infection and post-liver transplant diabetes: Data from $17000 \mathrm{HCV}$-infected transplant recipients", Alimentary Pharmacology \& Therapeutics, 41 (2), 209-17 (2015).

37- A. Mizoguchi, E. Mizoguchi, H. Takedatsu, R. S. Blumberg and A. K. Bhan, "Chronic intestinal inflammatory condition generates IL-10-producing regulatory B cell subset characterized by CD1d upregulation", Immunity, 16 (2), 219-30 (2002).

38- C. Mauri and M. Menon, "The expanding family of regulatory B cells", International Immunology, 27 (10), 47986 (2015).

39- C. Mauri and A. Bosma, "Immune regulatory function of B cells", Annual Review of Immunology, 30, 221-41 (2012).
40- I. Kalampokis, A. Yoshizaki and T. F. Tedder, "IL-10-producing regulatory B cells (B10 cells) in autoimmune disease", Arthritis Research \& Therapy, 15 (1), S1 (2013).

41- A. Floudas, S. Amu and P. G. Fallon, "New insights into IL-10 dependent and IL-10 independent mechanisms of regulatory B cell immune suppression", Journal of Clinical Immunology, 36 (1), 25-33 (2016).

42- B. Stanic, W. van de Veen, O. F. Wirz, B. Rückert, H. Morita, S. Söllner, et al., "IL10-overexpressing B cells regulate innate and adaptive immune responses", Journal of Allergy and Clinical Immunology, 135 (3), 771-80. e8 (2015) .

43- J. L. Maravillas-Montero and E. AcevedoOchoa, "Human B regulatory cells: The new players in autoimmune disease", Revista de Investigación Clínica, 69 (5), 243-6 (2017).

44- J-M. Berthelot, C. Jamin, K. Amrouche, B. Le Goff, Y. Maugars and P. Youinou, "Regulatory B cells play a key role in immune system balance", Joint Bone Spine, 80 (1), 18-22 (2013).

45- T. Yamaguchi, J. B. Wing and S. Sakaguchi, editors, "Two Modes of Immune Suppression by Foxp3+ Regulatory $\mathrm{T}$ Cells Under Inflammatory or Non-Inflammatory Conditions", Seminars in Immunology, 2011, Elsevier.

46- L. Wang, J. Qiu, L. Yu, X. Hu, P. Zhao and Y. Jiang, "Increased numbers of CD5+ CD19+ CD1d high IL-10+ B (regs), CD4+ Foxp3+ T (regs), CD4+ CXCR5+ Foxp3+ follicular regulatory $\mathrm{T}$ (TFR) cells in CHB or CHC patients", Journal of Translational Medicine, 12 (1), 251 (2014).

47- S. K. Lundy and D. L. Boros, "Fas ligandexpressing B-1a lymphocytes mediate CD4+-T-cell apoptosis during schistosomal infection: Induction by interleukin 4 (IL-4) and IL-10", Infection and Immunity, 70 (2), 812-9 (2002).

48- A. Yoshizaki, T. Miyagaki, D. J. DiLillo, T. Matsushita, M. Horikawa, E. I. Kountikov, et al., "Regulatory B cells control T-cell autoimmunity through IL21-dependent cognate interactions", Nature, 491 (7423), 264 (2012). 
49- K. Yanaba, J-D. Bouaziz, T. Matsushita, T. Tsubata and T. F. Tedder, "The development and function of regulatory $\mathrm{B}$ cells expressing IL-10 (B10 cells) requires antigen receptor diversity and TLR signals", The Journal of Immunology, 182 (12), 7459-72 (2009).

50- B. Rehermann, K-M. Chang, J. McHutchinson, R. Kokka, M. Houghton, C. M. Rice, et al., "Differential cytotoxic T-lymphocyte responsiveness to the hepatitis $\mathrm{B}$ and $\mathrm{C}$ viruses in chronically infected patients", Journal of Virology, 70 (10), 7092-102 (1996).

51- Y. Shao, C. M. Lo, C. C. Ling, X. B. Liu, K. T-P. Ng, A. C. Y. Chu, et al., "Regulatory B cells accelerate hepatocellular carcinoma progression via CD40/CD154 signaling pathway", Cancer Letters, 355 (2), 264-72 (2014).

52- D. J. DiLillo, T. Matsushita and T. F. Tedder, "B10 cells and regulatory B cells balance immune responses during inflammation, autoimmunity, and cancer", Annals of the New York Academy of Sciences, 1183 (1), 38-57 (2010).

53- Y. Xiu, C. P. Wong, J-D. Bouaziz, Y. Hamaguchi, Y. Wang, S. M. Pop, et al., "B lymphocyte depletion by CD20 monoclonal antibody prevents diabetes in nonobese diabetic mice despite isotypespecific differences in $\mathrm{Fc} \gamma \mathrm{R}$ effector functions", The Journal of Immunology, 180 (5), 2863-75 (2008).

54- M. S. Anderson and J. A. Bluestone, "The NOD mouse: A model of immune dysregulation", Annu. Rev. Immunol., 23, 447-85 (2005).
55- S. Hussain and T. L.Delovitch, "Intravenous transfusion of BCR-activated B cells protects NOD mice from type 1 diabetes in an IL-10-dependent manner", The Journal of Immunology, 179 (11), 7225-32 (2007).

56- S. M. Kamal and I. A. Nasser, "Hepatitis C genotype 4: What we know and what we don't yet know", Hepatology, 47 (4), 1371-83 (2008).

57- S. Blach, S. Zeuzem, M. Manns, I. Altraif, A-S. Duberg, D. H. Muljono, et al., "Global prevalence and genotype distribution of hepatitis $\mathrm{C}$ virus infection in 2015: A modelling study", The Lancet Gastroenterology \& Hepatology, 2 (3), 161-76 (2017).

58- J. E. Shaw, R. A. Sicree and P. Z. Zimmet, "Global estimates of the prevalence of diabetes for 2010 and 2030", Diabetes Research and Clinical Practice, 87 (1), 414 (2010).

59- C. R. de Lope, S. Tremosini, A. Forner, M. Reig and J. Bruix, "Management of HCC", Journal of Hepatology, 56, S75S87 (2012).

60- F. Capone, E. Guerriero, G. Colonna, P. Maio, A. Mangia, R. Marfella, et al., "The cytokinome profile in patients with hepatocellular carcinoma and type 2 diabetes", PLoS One., 10 (7), e0134594 (2015).

61- E. H. Harris, "Elevated liver function tests in type 2 diabetes", Clinical Diabetes, 23 (3), 115-9 (2005). 
Bull. Pharm. Sci., Assiut University, Vol. 42, 2019, pp. 9-18.

\begin{tabular}{|c|c|c|}
\hline (3) & نشرة العلوم الصيدليــــة & a \\
\hline
\end{tabular}

دور الخلايا التظيميه (reg) B (reg في الالتهاب الكبدي الوبائى

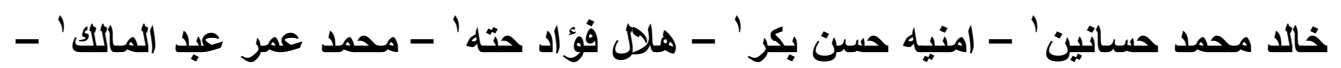

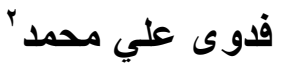

'قسم الميكروبيوجيا والمناعة ، كلية الطب ، جامعة أسيوط ، مصر

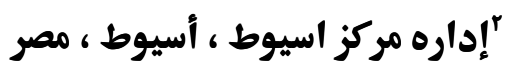

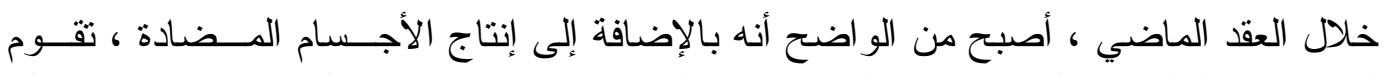

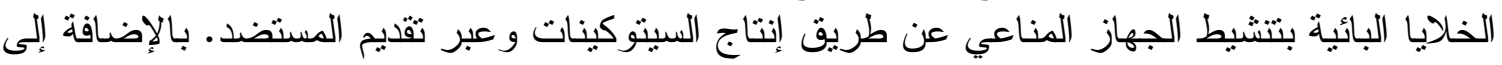

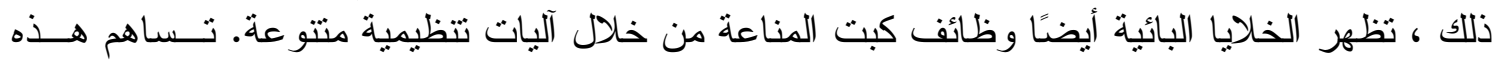

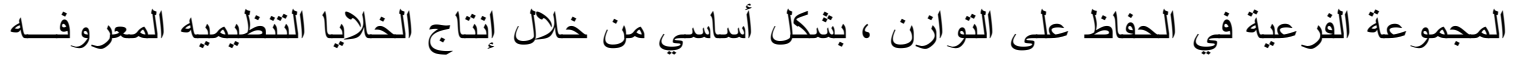
باسم (reg) وسوف نقوم بشرح دور هذه الخلايا التنظيميه B (reg) و علاقفتها بمرضـــي الالتهــاب الكبــدي الوبائي C ومرضي السكرى. 